used and it is then possible to measure the crystallographic angles, i.e. angles between crystal faces or lattice planes of the structure, and in this way to make the ordinary angle measurements even when the faces are not actually present. It is also possible to measure glancing angles and spacings, and thus to make determinations of the spacegroup to which the crystalline structure belongs. Two substances were investigated: (a) glyoxaline-4-sulphonic acid. The space group was determined and the crystal class - previously determined from the alternating presence of minute faces-was confirmed. (b) Glyoxaline. This substance does not form complete crystals. It was possible to measure crystal angles, and deduce the axial ratios, etc. The symmetry is monoclinic.

\title{
OBITUARY.
}

\section{Mr. R. B. Newton, I.S.O., F.G.S.}

Richard Bullen Newton, for many years an extensive contributor to the literature of invertebrate palaeontology, died on the 23rd January at the age of 71 . His early training was on the palaeontological staff of the Geological Survey, but in 1880 he was transferred to the Geological Department of the British Museum to help in the removal of the collections and their rearrangement at the new Natural History Museum at South Kensington. There he continued an active worker until shortly before his death, although officially retiring in 1920.

His numerous papers, reports on collections sent to the Museum, have dealt chiefly with Cretaceous and Tertiary Mollusca, and with the larger Tertiary Foraminifera. In addition to their purely palaeontological interest, they have contributed considerably to our knowledge of the stratigraphy of many distant regions, especially Africa and the East. They include his "Systematic List of the F. E Edwards Collection of British Oligocene and Eocene Mollusca" (1891), "Cretaceous Gastropods and Pelecypoda from Zululand" (1909), "Conchological Features of the Lenham Sandstones of Kent" (1916), and "Eocene Mollusca from Nigeria" (1922).

He was awarded the Wollaston Fund of the Geological Society in 1914, was President of the Malacological Society, 1910-12, and of the Conchological Society, 1913-15. On his retirement in 1920, the Imperial Service Order was conferred upon him in recognition of his long period of service.

His work has always been characterized by its extreme accuracy, and, in view of his very wide knowledge of fossils and of palaeontological literature, his loss will be greatly felt by all his colleagues.

L. R. C. 